\title{
IMPACT OF URINARY INCONTINENCE ON THE QUALITY OF LIFE AND FEMALE SEXUALITY
}

\author{
B. Adile **, P. Palma *, A. Pollina**, S. Bandiera**, M.L. Amico**, \\ A. Mercurio**, G. Gugliotta** \\ ** UROGYNECOLOGY DEPARTMENT "VILLA SOFIA C.T.O. HOSPITAL" - PALERMO \\ * UROGYNECOLOGY DEPARTMENT "CAMPINAS UNIVERSITY" - SAN PAOLO
}

\begin{abstract}
The prevalence of urinary incontinence is around 20\% of healthy middle-aged women. Incontinence has a negative impact on quality of life and sexuality. From August 2002 to January 2004, 30 patients (mean age 43 years) with stress urinary incontinence (59\%) overactive bladder (15\%0) and mixed incontinence (26\%) answered the ICIQSF (International Consultation on Incontinence Questionnaire - Short From) and FSFI (Female Sexual Function Index) questionnaires before and after treatment. The follow up ranged from 12 to 53 months. Mean ICIQ score was 17 and 7 before and after treatment respectively $(p<0,001)$. Overactive bladder showed the worst scores in all domains. The patients underwent surgery to increase desire $(p=0,02)$, satisfaction $(p=0,05)$ and total score $(p=0,02)$. In 13 patients the ICIQ score did not increase: desire $(p=0,01)$, satisfaction $(p=0,05)$ and total score $(p=0,01)$. Urinary incontinence significantly affects the quality of life. A sexuality evaluation in incontinence patients is recommended.
\end{abstract}


INTRODUCTION: Urinary incontinence affects at least 20\% of bealthy middleaged women. It is important that incontinence symptoms be treated since they affect not only the physiological, but also the psychological realms of a person's life. Researchers and clinicians are increasingly aware of the importance of identifying urinary incontinence, in particular when it causes distress or adversely affects the bealth-related quality of life of women.

MATERIAL AND METHODS: From August 2002 to January 2003, 30 patients (average age: 43 years) underwent a validated quality of life questionnaire in order to evaluate the impact of this condition within social life, self-esteem and sexual parameters.

RESULTS: urine leakage has a negative impact on the social aspect of life in 43\% of the patients, on self-esteem in $37 \%$ and on sexuality in $57 \%$.

CONCLUSION: urinary incontinence significantly affects the overall and sexual aspects of life in these patients

\section{INTRODUCTION}

The quality of life concept is directly related to the work of the World Health Organization (WHO), which defines health not only as the absence of disease, but also as a "state of physical, emotional and social wellbeing" (1). According to the International Continence Society (ICS), urinary incontinence (UI) represents hygienic and psychosocial problems for the patient $(2,3)$, determining a lower quality of life, an increase in depression and in the incidence of sexual dysfunctions (18). Women are more affected by urinary incontinence than men. In general, the prevalence of urinary incontinence varies between 3 and 11\% among adult men, and between 10 and 58\% among women (4). This study shows that urinary incontinence significantly affects the life of $20 \%$ of women $(5,6,7)$. The aim of this study is to evaluate the general quality of life and sexuality of incontinent patients.

\section{PATIENTS AND METHODS}

This is an open prospective study involving patients with urinary incontinence (UI), performed from August 2002 to January 2003, at the Hospital das Clínicas, Universidade Estadual de Campinas, UNICAMP, Brazil. The project was approved by the Research Ethics Committee with number 228/2001.

The patients' ages varied from 31 to 51 years (mean age: 43 years). The time from the onset of symptoms varies between 12 and 53 months. All the patients were multipara. Sixty percent of the women had incomplete primary education, and they were interviewed by the same researcher.

Two quality of life and sexuality questionnaires were used. The "Female Sexual Function Index (FSFI)" questionnaire (16) verified aspects related to sexual response and possible dysfunctions, as well as encouraging the investigation of the sexual function index scores for the following 
sexuality areas: libido, excitement, lubrication, orgasm, pleasure and pain. The "Impact of Urinary Incontinence on the Sexual Response/RJ (IIURSRJ)" questionnaire (6) observed interferences of UI in the sexual, social and self-esteem spheres. It evaluated questions regarding the adaptation of women with the same symptoms, their routines and feelings, as well as making it possible to characterise the differences in sexual behaviour before and after the UI.

The Wilcoxon's test was used for statistical analysis. When no comparison was possible, the analysis was made using the "Statistica" software. The Wilcoxon's test was also used to establish differences between the classification of other variables before and after urinary incontinence. The $\mathrm{p}$ values lower than 0.05 indicate significant differences of behaviour before and after the appearance of the symptoms.

\section{RESULTS}

Most of the patients were married (86.67\%); all of them had only one partner; $63.33 \%$ referred that they are Catholics, 60\% had an incomplete elementary education, and in $63.33 \%$ of the cases they performed daily or similar professional activities that did not require any specialisation.

Concerning the effects of UI on their daily life (table 1), the main problem identified was the bad smell and the need to use pads for $43 \%$, followed by involuntary leakage and wetness for $40 \%$. The others indicated the need for surgery (7\%), urinary frequency $(3 \%)$, stress incontinence (3\%) and urine leakage in the presence of their husband (3\%).

Table I - The most frequent problems

Problem

(\%)

Bad smell and use of tampon 13

(43)

Involuntary loss and wetness 12

(40)

Surgery indication

2

(07)

Stress incontinence $\quad 1$

(03)

Urinary frequency

(03)

Urine loss in the presence

of the husband

$1(03)$

Furthermore, these problems caused alterations to daily, professional and social activities in $43 \%$ of the cases. There was significant loss of self-esteem, substituted by the feeling of being of less value in $37 \%$ of the evaluated patients, and $57 \%$ of them also presented a decreasing quality of their sexual life.

Of the thirty women evaluated, 23 (76.67\%) related that they already had urinary leakage during the sexual intercourse. Among these women, 17 (73.91\%) considered this leakage as a negative interference in their sexual life against six who did not present this reference. Two (11.76\%) of the 17 women who indicated UI as a negative influence on their sexual life, considered this influence mild; four (23.53\%) evaluated it as moder- 
ate and eleven (64.71\%) as severe.

The consequences of urinary loss for the patients were: anxiety (13/43.33\%); depression (11/36.67\%), shame $(4 / 13.33 \%)$ and hate $(2 / 6.67 \%)$. These values suffered alterations when leakages that occurred in the presence of other people were evaluated: anxiety (6/22.22\%), depression (18/66.67\%) and shame (3/11.11\%).

Regarding the frequency of these women's sexual intercourse before and after presenting UI, 13 (43.33\%) did not present alterations and 17 (56.67\%) presented a decrease. In those who referred negative alterations, the sexual activity changed from weekly to monthly ( $7 / 41.18 \%)$, from daily to weekly $(5 / 29.41 \%)$, from daily to monthly (3/17.65\%), from monthly to yearly $(1 / 5.88 \%)$ and from weekly to no relationship $(1 / 5.88 \%)$. The informed Wilcoxon's test indicated a significant difference in sexual relationships before and after the appearance of UI $(\mathrm{p}<0.001)$. However, other factors such as age and length of relationship may have interfered with the result. Table 2 shows the situations with no change, demonstrated in italic, and those with a decrease, in bold.

By using the Wilcoxon's test again, differences between the classification of other variables before and after the onset of incontinence were established. Ten items related to sexuality were studied: desire, excitement, vaginal lubrication, general caresses, genital caresses, oral sex in the partner and in the patient, vaginal penetration, anal penetration and orgasm.

Six of the ten items studied before and after the onset of UI presented significant differences. There was a decrease of the following aspects: desire $(\mathrm{p}=0.008)$; genital caresses $(p=0.009)$ and general caresses $(\mathrm{p}=0.003)$; vaginal penetration $(0.004)$, anal penetration $(\mathrm{p}=0.028)$ and orgasm $(\mathrm{p}=0.007)$. Other aspects such as: excitement, lubrication and oral sex in the partner and patient did not present significant differences.

\section{DISCUSSION}

Urinary incontinence (UI) is a common problem that constitutes a significant demand for social programmes, and causes frequent discussions among health care providers concerning the best way to prevent and treat it.

Recently, many studies have approached the quality of life in incontinent patients, especially from the patient's point of view. Several self-administered questionnaires proposing objective measurements of the emotional domain can be found in literature, although with divergent results.

The impact of UI on patients' life is not directly related to the volume of urine loss, although women who present fewer symptoms tolerate the complaint better than those with more intense urinary losses (8). Since tolerance to incontinence varies among the patients and there is a tendency to adapt to the problem, epidemiologic studies on the impact of its symptoms on the quality of life should take this aspect into consideration. 
The quality of life includes a series of parameters, including physical and behavioural function, vitality, mental sanity and social intervention. The most relevant domains for the group studied included the quality of relationships, psychological and sexual wellbeing. Sexual satisfaction is an important indication of satisfaction with life in general. It is known that being unable to have satisfactory sexual intercourse causes decreases in self-esteem, generating emotional and marital tension.

Health problems are followed by negative feelings that cause an experience of inferiority, fear, hate, anxiety and depression. The threat to the patient's health and its meaning for the patient may affect the quality of her personal relationships (with relatives, husband and friends).

Anxiety and depression is observed in a significant number of patients with a UI complaint who look for medical assistance. A recent research demonstrated that in animals the reduction of monoamine levels on the Central Nervous System, such as the noradrenaline and serotonin, causes vesical hyperactivity and depression (10). Lempinem et al. observed that $44 \%$ of incontinent patients presented depression (9). There is evidence of loss of self-esteem, social restriction, and increased incidences of depression, neurosis and sexual dysfunctions due to UI, mainly in older patients (18).

Furthermore, patients with emotional difficulties may present serious problems regarding acceptance and adherence to any therapy. It is necessary to describe these patients' pro- files and establish more effective treatment protocols.

The average age of the women analysed in this study was 43 years, with an evolution of the symptoms that varied between 12 and 53 months. The relationship between the patient's age, the time between the appearance of the complaint, the search for medical assistance and the extent of emotional involvement have shown conflicting results in literature $(11,12)$. However, most of the controlled and randomised studies have not found any association among the patient's age, duration of the symptoms and the extent of anxiety or depression (9).

This study demonstrated that $57 \%$ of the patients referred a negative alteration of the frequency of sexual intercourse, and among these 17 referred a negative impact on their sexual life, 11 (64.71\%) referred a severe effect. Abdo and col. studied the sexual life of 1,502 healthy Brazilian women and concluded that in 34.6\% the main complaint is the lack of desire and in 29.3\% the dysfunction of the orgasm (17). These results demonstrated that there is a reasonable number of sexual dysfunctions in the general Brazilian population and that the data in this paper may be higher due to the presence of UI. The findings in the literature present values of involvement of the sexual sphere at around 30\%, demonstrating that the indexes of the patients of this study are comparatively nearer to those of people with dysfunctions.

Another possible explanation of these results is the fact that the group analysed is between 31 and 51 years 
of age, since according to the studies the involvement of the sexual sphere is greater in women over 50 (15). Another factor is that this study was not designed according to the diagnosis of each group, whereas the research carried out by Gordon and col. (15) demonstrated that women with UI due to detrusor overactivity, diagnosed with a urodynamic evaluation, presented a greater involvement of the sexual function than those with UI caused by other factors. Grouping a higher number of patients with detrusor overactivity may have occurred, contributing to the elevated index of sexual complaints.
Similar studies are important for the characterisation of patients with UI in different institutions, as well as identifying aspects that assure a good quality of life and the planning of therapeutic lines to solve each case.

\section{CONCLUSION}

Urinary incontinence has a negative impact on self-esteem, social and sexual life, and may result in anxiety and depression. The management of urinary incontinence should include the evaluation of self-esteem, social and sexual life as well. 


\section{References}

1. CORCOS J., BEAUlieu S., DONOVAN J., NAUGHTON M., MOMOKAZU G. et al. :

Quality of life assessment in men and women with urinary incontinence.

J Urol 2002, 168:896-905.

2. BATES P., BRADLEY W.E., GLEN E., GRIFFITHS D., MELCHIOR H., ROWAN D. et al. :

The standardization of terminology of lower urinary tract function.

J Urol 1979, 121:551-554.

3. BLAIVAS, J.G., APPELL, R.A., FANTL, J.A. et al. :

Standards of efficacy for evaluation of treatment outcomes in urinary

incontinence: recommendations of the Urodynamic Society.

Neurourol Urodyn,16: 145, 1997.

4. HUNSKAAR S., ARNOLD E.P., BURGIO K., HERZOG A.R, MALLETT V.T. : Epidemiology and natural history of urinary incontinence.

In: Incontinence. Edited by P Abrams, S Khoury and A Wein. London: Health Publications 1999,199-226.

5. BURGIO K.L., MATTHEWS K.A., ENGEL B.T. :

Prevalence, incidence and correlates of urinary incontinence in bealthy middle-aged women.

J Urol 1991, 146:1255-1259.

6. REZENDE R.C.A. :

A Influência da Incontinência Urinária na Resposta Sexual Feminina.

Rio de Janeiro: Mestrado em Sexologia da Universidade Gama Filho, 2000.

Dissertação de Mestrado.

7. BRADWAY C. :

Urinary incontinence among older women. Measurement of the effect on bealth-related quality of life.

J Gerontol Nurs. 2003 Jul. 29(7): 13-19.

8. WYMAN J.F., HARKINS S.W., CHOI S.C. et al. :

Psychosocial impact of urinary incontinence in women.

Obstet Gynecol 1987, 70:378-81.

9. STACH-LEMPINEN B., HAKALA A.L., LAIPPALA P., LEHTINEN K., METSANOJA R., KUJANSUU E. :

Severe depression determines quality of life in urinary incontinent women.

Neurourol Urodyn 2003, 22:563-568. 
10. STEERS W.D., LEE K.S. :

Depression and incontinence.

World J Urol 2001,9:351-5.

11. HUNSKAAR S., VINSNES A. :

The quality of life in women with urinary incontinence as measured by the sickness impact profile.

J Am Geriatr Soc 1991, 39:378-82.

12. KELLEHER C.J., KHULLAR V., CARDOZO L.D. :

The impact of urinary incontinence on quality of life.

Neurourol Urodyn 1993, 12:388-98.

13. TEMML C., HAIDINGER G., SCHMIDBAUER J., SCHATZL G., MADERSBACHER S. :

Urinary incontinence in both sexes: prevalence rates and impact on quality of life and sexual life.

Neurourol Urodyn 2000, 19:259-71.

14. YIP S.K., CHAN A., PANG S. et al. :

The impact of urodynamic stress in incontinence and detrusor overactivity on marital relationship and sexual function.

Am J Obstet Gynecol 2003, 188(5): 1244-48.

15. GORDON D., GROUTZ A., SINAI T. et al. :

Sexual function in women attending a urogynecology clinic.

Int Urogynecol J Pelvic Floor Dysfunct 1999, 10:325-8.

16. ROSEN R., BROWN C.J., HEIMAN et al. :

The Female Sexual Function Index (FSFI): A Multidimensional Self-reportInstrument for the Assessment of Female Sexual Function.

Journal of Sex and Marital Therapy 2000, 26: 191-208.

17. ABDO C.H.N., OLIVEIRA JR. W.M., MOREIRA E.D. et al. : Perfil Sexual da População Brasileira: Resultados do Estudo de Comportamento Sexual (ECOS) do Brasileiro.

Revista Brasileira de Medicina, abril, 2002, 59(4): 250-57.

18. RAFNER R.J., STANTON S.L., GUY L.A. :

A psychiatric study of women with urgency and urgency incontinence.

Br J Urol, 1977, 49: 211-14. 